\title{
FEATURES OF PSYCHOLOGICAL EXPERIENCES IN SEVERE QUARANTINE DURING THE COVID-19 PANDEMIC: THE ROLE OF TOLERANCE FOR UNCERTAINTY
}

DOI: 10.36740/WLek202106104

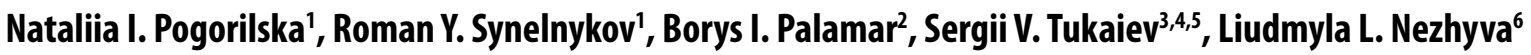 \\ ${ }^{1}$ FACULTY OF PSYCHOLOGY, TARAS SHEVCHENKO KYIV NATIONAL UNIVERSITY, KYIV, UKRAINE \\ 2 BOGOMOLETS NATIONAL MEDICAL UNIVERSITY, KYIV, UKRAINE \\ ${ }^{3}$ EDUCATIONAL AND SCIENTIFIC CENTRE "INSTITUTE OF BIOLOGY AND MEDICINE", TARAS SHEVCHENKO KYIV NATIONAL UNIVERSITY, KYIV, UKRAINE \\ ${ }^{4}$ INSTITUTE OF JOURNALISM, TARAS SHEVCHENKO KYIV NATIONAL UNIVERSITY, KYIV, UKRAINE \\ ${ }^{5}$ RESEARCH INSTITUTE, NATIONAL UNIVERSITY OF UKRAINE ON PHYSICAL EDUCATION AND SPORT, KYIV, UKRAINE \\ ${ }^{6}$ PEDAGOGICAL INSTITUTE, BORYS GRINCHENKO KYIV UNIVERSITY, KYIV, UKRAINE
}

\begin{abstract}
The aim: To examine the features of experiences during quarantine relating to the tolerance for uncertainty.

Materials and methods: 306 volunteers aged 18-65 years participated in this study. All participants were tested during strict quarantine in April 2020. In order to diagnose the personality traits related to ambiguity tolerance, we used Budner's scale of tolerance-intolerance of ambiguity. To determine the features of experiences we used the survey, which included 40 statements and 12 emotional states related to the cognitive, emotional-evaluative, and behavioral components of the person's self-image.

Results: The overwhelming majority of volunteers perceive the pandemic as a dangerous, threatening, uncertain situation and make hasty decisions on the base of polar judgments, react with anxiety, attempt to avoid uncertainty, rejection of everything unusual. Their experiences were filled with feelings of powerlessness and deterioration in mood. For the majority of our subjects, the situation of uncertainty is the source of intolerance. Negative consequences appeared in the behavior (loss of time management skills, laziness). There are direct relationships between the factor of shock and anxiety with the sources of intolerance, novelty and complexity, and general intolerance. The cognitive component of the experience was the least pronounced and involved only after an emotional experience.

Conclusions: It has been established that cognitive rethinking of the self-isolation during the COVID-19 pandemic is possible after an emotional response and leads to a change in the behavioral stereotypes.
\end{abstract}

KEY WORDS: COVID-19 pandemic; tolerance-intolerance of ambiguity, coping strategies, behavior

\section{INTRODUCTION}

The global nature of the COVID-19 pandemic, quarantine in many countries at different levels have led to radical changes in the daily life of people. The COVID-19 pandemic, accompanying problems in medicine, and the economic crisis have changed behavior, introduced a high level of uncertainty into all aspects of everyday life [1]. The scale of the threat posed to personal safety by COVID-19 has led to a significant increase in the number of mental health disorders [2] and therefore meet the definition of a traumatic event [3]. The triad of psychological factors associated with the response to the current pandemic are intolerance of uncertainty, conspiracy ideation, and moral disengagement. It has been established that intolerance to uncertainty is one of the critical factors for compliance with the regime of isolation and social distancing introduced by the authorities [4]. Intolerance of uncertainty arises from negative perceptions of uncertainty and its consequences [5]. In conditions where uncertainty is perceived especially intensely, intolerance to uncertainty against the background of aggravating emotional problems leads to the development of anxiety disorders $[6 ; 7 ; 8 ; 9]$. Increased anxiety in a pandemic leads to the development of stress disorders. There is a direct link between anxiety and the risk of burnout [10]. Uncertainty intolerance is fundamental to anxiety [11], state of disturbance [12], agoraphobia, obsessive-compulsive disorder, depression, and eating disorder [13]. The need for predictability (as a variable of intolerance of uncertainty) together with indecisiveness and self-oriented perfectionism are unique correlates of trait worry, generalized anxiety disorder [14]. The response to uncertainty determines how people cope with the pandemic and becomes a factor of mental health. The intolerance of uncertainty appears to be associated with the ability to regulate stress during the COVID-19 pandemic [15]. The increased level of uncertainty in society led to intense and general distress, the development of a number of mental disorders, deterioration of mood, 
Table I. Completeness of components of the response to the quarantine situation

\begin{tabular}{|c|c|c|c|}
\hline \multirow[t]{2}{*}{$\begin{array}{l}\text { Name of the } \\
\text { component }\end{array}$} & \multirow[t]{2}{*}{ Criteria } & \multicolumn{2}{|c|}{ Completeness } \\
\hline & & Positive pole & Negative pole \\
\hline \multirow{2}{*}{ Cognitive } & \multirow{2}{*}{$\begin{array}{l}\text { Awareness, } \\
\text { consciousness }\end{array}$} & \multirow{2}{*}{$\begin{array}{c}\text { Analysis, comprehension, awareness of } \\
\text { one's thoughts, feelings, motives and } \\
\text { behavior, awareness and consciousness } \\
\text { of both negative and positive aspects of } \\
\text { the quarantine situation }\end{array}$} & $\begin{array}{c}\text { Careful awareness of the quarantine } \\
\text { situation, careful, obsessive analysis of } \\
\text { thoughts, feelings, motives. } \\
\text { Consciousness of only the negative aspect } \\
\text { of quarantine }\end{array}$ \\
\hline & & & $\begin{array}{c}\text { Complete disregard for quarantine } \\
\text { information, lack of understanding. } \\
\text { Perceiving quarantine only as recreation and } \\
\text { ignoring the possible dangers associated } \\
\text { with COVID-19 }\end{array}$ \\
\hline Emotional & $\begin{array}{l}\text { Attitudes and } \\
\text { experiences to the } \\
\text { quarantine situation }\end{array}$ & $\begin{array}{c}\text { Sensuality, emotionality, vitality index, } \\
\text { view of the quarantine situation from a } \\
\text { positive point of view, belief in a positive } \\
\text { end to the situation, lack of excessive fear, } \\
\text { confidence, calm }\end{array}$ & $\begin{array}{l}\text { Decreased vitality, fatigue, despair, fear, } \\
\text { anxiety, obsession only with their own } \\
\text { emotional state, fatalistic perception of the } \\
\text { consequences of quarantine }\end{array}$ \\
\hline Behavioral & Effectiveness & $\begin{array}{l}\text { Changes in behavior in a quarantine } \\
\text { situation, the use of various copings to } \\
\text { transform emotions (sports, changes } \\
\text { in eating habits, etc.), the statement } \\
\text { of minor changes (already a month in } \\
\text { quarantine) of daily routine, the ability to } \\
\text { change one's own plans and decisions }\end{array}$ & $\begin{array}{l}\text { Being stuck in the situation (fixation of } \\
\text { significant changes in the daily routine, } \\
\text { inability to get down to business), the } \\
\text { statement of a significant change in habits } \\
+ \text { strong emotional experiences, the } \\
\text { statement of one's own disorganization, etc. }\end{array}$ \\
\hline
\end{tabular}

increased anxiety, depression [16], burnout, acute stress disorder and posttraumatic stress disorder (PTSD) [17], obsessive-compulsive disorders.

The above-mentioned analysis shows that intolerance to uncertainty has a significant direct impact on the mental well-being of an individual. At the same time, the influence of the emotional experience of a person and its components (cognitive, emotional-evaluative and behavioral) turned out to be beyond the attention of researchers.

\section{THE AIM}

To identify the features of experiences during quarantine in connection with the emotional experience of the individual and its cognitive, emotional-evaluative and behavioral components.

Assess the impact of tolerance of uncertainty on emotional experiences during quarantine.

\section{MATERIALS AND METHODS}

The study was conducted via the Internet using the Google form. The poll took place during the week from 09.04.2020 to 16.04.2020. This period was chosen in order to avoid the diagnosis of acute feelings about quarantine, which could be inherent in the first stage (from 12.03 to 31.03.2020) and at the time of confirmation of the second stage (from 01.04 to 24.04 .2020 ). The period was characterized by a strict ban on leaving homes without an urgent need for the majority of the population. The study involved 306 people, including 77 men and 229 women.
The purpose of the survey was to diagnose the characteristics of experiences during quarantine and to understand these features in people with different levels of tolerance for uncertainty. A corresponding questionnaire, which included questions to clarify the specifics of the experience, was developed for realization. In order to determine the individual level of tolerance for uncertainty, we use a 16 item Likert-type scale of tolerance-intolerance of ambiguity, developed by the American psychologist Stanley Budner [18], which was translated and adapted by G.U. Soldatova in 2003 [19].

Statistical processing of data was carried out using the methods of mathematical statistics. Correlation analysis (the Pearson's correlation coefficient) was used to establish relationships between variables. The factor analysis was used to study the relationship between the cognitive, emotional-evaluative and behavioral components of the personality.

\section{RESULTS AND DISCUSSION}

In a holistic picture of the individual's self-image $[20 ; 21]$ it is accepted to consider cognitive, emotional-evaluative and behavioral components. The cognitive component usually includes the individual's perceptions of himself, which cause the selectivity of perception. Therefore, the cognitive component included questions that reveal the degree of human awareness of the situation with the disease in the country, understanding the dangers and the need for compliance with quarantine restrictions. The emotional-evaluative component included all the parameters of evaluation, which reveal a caring atti- 
Nataliia I. Pogorilska et al.

Table II. Frequency analysis of emotional experiences during the quarantine

\begin{tabular}{|c|c|c|c|c|c|}
\hline \multirow{2}{*}{ Emotional experiences } & \multicolumn{5}{|c|}{ Frequency of the corresponding degree of expression, $\%$} \\
\hline & Low & Below average & Average & Above average & High \\
\hline Calm & 11,8 & 30,2 & 27,2 & 21,3 & 9,5 \\
\hline Carefree & 33,1 & 31,1 & 23,9 & 8,2 & 3,6 \\
\hline Excited & 24,6 & 23,0 & 27,9 & 16,4 & 8,2 \\
\hline Isolated & 22,3 & 14,4 & 25,2 & 18,7 & 19,3 \\
\hline Abandoned & 58,4 & 14,4 & 12,8 & 7,9 & 6,6 \\
\hline Baffled & 37 & 26,6 & 18,4 & 8,9 & 9,2 \\
\hline Indifferent & 37,7 & 26,6 & 21,3 & 9,8 & 4,6 \\
\hline Tired & 25,9 & 22,6 & 23,9 & 15,4 & 12,1 \\
\hline Depressed & 31,1 & 25,9 & 18,0 & 13,1 & 11,8 \\
\hline Energetic & 17,4 & 33,1 & 30,8 & 14,4 & 4,3 \\
\hline Elevated & 30,8 & 31,8 & 24,3 & 8,9 & 4,3 \\
\hline Worried & 18,7 & 22,3 & 24,6 & 18,7 & 15,7 \\
\hline
\end{tabular}

tude to oneself and one's life. This component included the features of the emotional response to quarantine restrictions, as well as the question of identifying the dominant emotional experience during the quarantine period. The behavioral component combines parameters that reveal coping strategies and behavioral changes that occurred during quarantine. In combination with the dominant emotional experience, behavioral changes revealed a general state of self-perception during such a stressful situation as quarantine caused by COVID-19. In total, the subjects worked with 40 statements and 12 emotional states.

The above-mentioned ideas formed the basis for the scheme of empirical research (Table I).

To clarify the selected structure, a factor analysis was conducted, which detailed the

understanding of the manifestation of cognitive, emotional and behavioral components. In total, eight factors explain $57.5 \%$ of the total variance. The first factor explains almost $11.19 \%$ of the variance. Factor covered the items that studying the negative effects of quarantine on behavioral level.

The second factor ( $8 \%$ of the total variance) combined items that reveal negative feelings about the loss of a normal lifestyle.

The third factor explained the $7.8 \%$ variance and, in our opinion, is the factor of experiencing restrictions on freedoms.

The fourth factor covered $7.38 \%$ of the total variance - it can be called a factor of change, innovation in life from quarantine, because this block combines items "quarantine helped re-evaluate my life values" (0.794), "quarantine helps me look at my lifestyle on the other hand" (0.721), "due to quarantine I began to treat my health differently" $(0.623)$ and "during quarantine my habits changed" (0.603).

The statements included in the fifth factor (fifth factor 7.07\% of the total variance) included awareness-raising questions (cognitive aspect): "I know exactly how many people are infected in my country today" (0.599), "News about the COVID-19 pandemic irritates me more than informs" (-0.417), etc.

The sixth factor covered $5.5 \%$ of the total variance, and, in our opinion, it is a factor of depression, helplessness, be- cause the issues included in the factor reveal the growth of dissatisfaction, loss of taste for life, etc. In particular, these are the following issues: "During quarantine I stopped enjoying food" (0.553), "I feel that little depends on me in this situation" (0.537) and "I get annoyed more than usual" (0.449), etc.

The seventh factor explained $5.24 \%$ of the total variance, and combined questions that reveal their own negative emotional experiences from being quarantined.

The eighth factor covered $5.15 \%$ of the total variance and singled out the points that relate to feelings for loved ones, fear that they will get sick.

With the help of factor analysis, we were able to clarify the structure of the components of the attitude and experience of the quarantine situation, it was found that an essential component is the experience of restriction of freedom. At the behavioral level, on the one hand, respondents emphasize the negative consequences of loss of organization, laziness, and on the other hand, note that the quarantine situation has forced to reconsider ones' lives, attitudes to health.

As a result of determining the normative indicators of experience, we established the levels of experience - high $\left(3^{\text {rd }}\right)$, medium $\left(2^{\text {nd }}\right)$ and low $\left(1^{\text {st }}\right)$. Frequency analysis found that experience at the cognitive level is mostly present in people at the first and second levels. Experience at the third level is typical only for $6.9 \%$ of the sample ( 21 people). This indicates that a high level of analysis, comprehension, awareness of one's thoughts, feelings, motives and behavior, awareness and consciousness of both negative and positive aspects of the quarantine situation is represented in a small number of subjects.

Preliminary factor analysis showed the dominance of the emotional component (primarily negative experiences), which interferes with understanding the situation. To clarify the emotional experiences, self-reports of estimates of the degree of expression of these experiences were processed.

The analysis of descriptive statistics revealed the dominance of such emotional experiences as anxiety $(\mathrm{m}=2.9)$ and calm $(\mathrm{m}=2.87)$. According to our results, abandonment $(\mathrm{m}=1.89)$ 
Table III. Frequency analysis of the severity of tolerance and its components, $\%$

\begin{tabular}{cccc}
\hline & Tolerance & & Intolerance \\
\cline { 2 - 4 } & Low & Average & High \\
\hline Novelty & 1,3 & $\mathbf{8 5 , 6}$ & 13,1 \\
\hline Complexity & 0,3 & 15,7 & $\mathbf{8 4}$ \\
\hline Unresolvedness & 1,3 & $\mathbf{8 1 , 4}$ & 17,3 \\
\hline General intolerance & 1 & 29,4 & $\mathbf{6 9 , 6}$ \\
\hline
\end{tabular}

was the least pronounced emotional experience.

To further clarify the emotional experiences, a frequency analysis of the obtained indicators was performed (Table II). Emotional experiences dominated by low grades were experienced as carefreeness, abandonment, confusion, indifference, fatigue, depression and elation.

The results showed that most respondents $46.4 \%$ (142) were happy because they were able to be alone, $18.6 \%(75)$ were able to spend time with themselves, $15.4 \%$ (47) were able to sleep, $4.2 \%$ (13) were able to stay with relatives and $15.3 \%$ (47) found other positives features of quarantine. Of the things that respondents did not like the most because of their quarantine, was the impossibility of walking in nature for $40.2 \%$ (123), inability to communicate with friends for $29.4 \%$ (90) or to stay with friends, $12.4 \%$ (38), and $18 \%$ (55) indicated other negatives of quarantine.

In order to better understand the structure of emotional experiences, a factor analysis was performed. The expediency of factor analysis was indicated by the KMO indicators $(0.808)$ and the statistical significance of the Bartlett's test $(0.000)$. After factorization, the following three factors were obtained, which together explained $68,6 \%$ of the sample. The first factor included the experiences of puzzled (0.847), depressed (0.830), agitated (0.805), abandoned (0.753), isolated (0.717) and tired $(0.653)$. The second factor included such variables as energetic (0.902), sublime (0.833) and calm (0.657). And the third included the following variables: indifferent $(0.752)$ and carefree (0.595).

Correlation analysis helped to understand the resources of the experience stages. The first stage is associated with emotional 0.486 (at $\mathrm{p}=0.000)$ and behavioral $0.525(\mathrm{p}=0.000)$ components. The second stage of experience is associated with a behavioral $(-0.373$ at $\mathrm{p}=0.000)$ component. The third stage is associated with emotional $(-0.151$ at $\mathrm{p}=0.008)$ and cognitive $(-0.251$ at $\mathrm{p}=0.000)$ components.

The next step in analyzing the experiences of the COVID-19 pandemic and the quarantine constraints caused by the pandemic was to understand the place of these experiences of tolerance for uncertainty.

Frequency analysis of the severity of tolerance-intolerance and its components revealed certain trends (Table III).

The results show that the vast majority of respondents (69.6\% of the sample) are characterized by the perception of uncertain situations as a source of threat; the tendency to make polar judgments of the "black and white" type; attempts to make hasty decisions, often without taking into account the real state of affairs; the desire for obvious and unconditional acceptance or rejection in relationships with other people; inability to think in terms of probabilities and attempts to avoid the opaque and vague; tendency to react with anxiety to unclear situations; the need for categorization; impossibility to assume the presence of positive and negative characteristics within one object; dichotomy of perception; inability to perceive contradictory and rapidly changing stimuli; search for security and attempts to avoid uncertainty; granting preference to something familiar, rejection of everything unusual. For most of our respondents (84\%) the source of intolerance is the complexity of the uncertainty situation.

In addition, the presence of tolerance to uncertainty between our selected factor of emotional experiences (shock factor) and anxiety, which has direct links with sources of intolerance novelty $(0.205$ at $p=0.000)$, complexity $(0,119$ at $p=0.037)$ and general intolerance ( 0.157 at $p=0.006$ ), was defined. This clarifies the understanding of the source of shock and concern - the situation of isolation, strict quarantine restrictions have become a difficult, unfamiliar, threatening situation.

The emotional component is filled with feelings for oneself and loved ones, feelings of helplessness, low mood and negative feelings about the loss of a normal way of life.

Low assessments of carelessness are explained by the fact that quarantine is not perceived as a vacation or rest (holidays), but makes study participants think about finding job opportunities, new ways of working, etc. Regarding the confusion, which is almost not typical for our subjects, most of the respondents understand why this situation has arisen, because people are not just in quarantine, but also received an explanation why they appeared to be there. It is gratifying that the subjects noted low rates of fatigue and depression, which indicates a belief in a positive end to the situation.

The factor analysis indicated the stages of experiencing quarantine: shock and anxiety, euphoria and elation, acceptance and humility.

\section{CONCLUSIONS}

Thus, in general, the following conclusions can be drawn: the studied primarily responded to the pandemic situation with emotional experiences. These experiences were filled not only with feelings for themselves, but also for the ir loved ones. Also in these experiences there were feelings of helplessness and low mood, negative feelings about the loss of a normal way of life. As for behavior, on the one hand, respondents stated that there are negative consequences (loss of organization, laziness), and on the other hand, noted that the quarantine situation has opened up new opportunities, forced to reconsider their lives, attitudes to health. 
Detailed consideration of emotions complemented the emotional component of experiences. Thus, the studied respondents are concerned, calm and do not feel abandoned. This seemingly paradox is explained by the availability of technical means and the prevalence of remote communication programs.

The cognitive component of the experience of the quarantine situation through COVID-19 was the least pronounced.

\section{REFERENCES}

1. Rettie H., Daniels J. Coping and tolerance of uncertainty: Predictors and mediators of mental health during the COVID-19 pandemic. American Psychologist. 2020. D0I: 10.1037/amp0000710.

2. Galea S., Merchant R. M., Lurie N. The mental health consequences of COVID-19 and physical distancing: the need for prevention and early intervention. JAMA internal medicine. 2020; 180(6): 817-818. DOI: 10.1001/jamainternmed.2020.1562.

3. American Psychiatric Association. Diagnostic and statistical manual of mental disorders (DSM-5 ${ }^{\oplus}$ ). 5th ed. American Psychiatric Pub. 2013.

4. Maftei A., Holman A.C. Beliefs in conspiracy theories, intolerance of uncertainty, and moral disengagement during the coronavirus crisis. Ethics \& Behavior; 2020, p. 1-11.DOl: https://doi.org/10.1080/10508422.2020.1843171.

5. Satici B., Saricali M., Satici S. A., Griffiths M. D. Intolerance of uncertainty and mental wellbeing: serial mediation by rumination and fear of COVID-19. International Journal of Mental Health and Addiction. 2020; 1-12. D0l: https://doi.org/10.1007/s11469-020-00305-0.

6. Rosen N. 0., Ivanova E., Knäuper B. Differentiating intolerance of uncertainty from three related but distinct constructs. Anxiety, Stress \& Coping. 2014; 27(1): 55-73.

7. Tolin D.F., AbramowitzJ.S., Brigidi B.D., Foa E. B. Intolerance of uncertainty in obsessive-compulsive disorder. Journal of anxiety disorders. 2003; 17(2): 233-242. DOl: https://doi.org/10.1016/S0887-6185(02)00182-2.

8. Fergus T. A. A comparison of three self-report measures of intolerance of uncertainty: An examination of structure and incremental explanatory power in a community sample. Psychological assessment. 2013; 25(4): 1322-1331. D0l: 10.1037/a0034103.

9. Morriss J., Christakou A., Van Reekum C. M. Nothing is safe: Intolerance of uncertainty is associated with compromised fear extinction learning. Biological psychology. 2013; 121(B):187-193.D0l: https: //doi. org/10.1016/j.biopsycho.2016.05.001.

10. Tukaev S., Palamar B., Vasheka T., Mishyiev V. Sindrom emotsional'nogo vygoraniya. Psikhofiziologicheskiye aspekty [Burnout syndrome. Psychophysiological aspects] Psychiatry, Psychotherapy and Clinical Psychology. 2020; 11(4): 791-801. (in Russian).

11. Laugesen N., Dugas M. J., Bukowski W. M. Understanding adolescent worry: The application of a cognitive model. Journal of abnormal child psychology. 2003; 31(1): 55-64. D0l: https://doi. org/10.1023/A:1021721332181.

12. Greco V., Roger D. Coping with uncertainty: The construction and validation of a new measure. Personality and individual differences. 2001; 31(4): 519-534. D0l: https://doi.org/10.1016/S0191-8869(00)00156-2.

13. McEvoy P. M., Hyett M. P., Shihata S. et al. The impact of methodological and measurement factors on transdiagnostic associations with intolerance of uncertainty: A meta-analysis. Clinical psychology review. 2019; 73: 101778. D0l: https://doi.org/10.1016/j.cpr.2019.101778.

14. Koerner N., Mejia T., Kusec A. What's in a name? Intolerance of uncertainty, other uncertainty-relevant constructs, and their differential relations to worry and generalized anxiety disorder. Cognitive Behaviour Therapy. 2017; 46(2): 141-161. D0l: 10.1080/16506073.2016.1211172.
15. Di Monte C., Monaco S., Mariani R., Di Trani M. From Resilience to Burnout: psychological features of Italian General Practitioners during COVID-19 emergency. Frontiers in Psychology. 2020; 11: 2476.

16. Parlapani E., Holeva V., Nikopoulou V. A. et al. Intolerance of uncertainty and loneliness in older adults during the COVID-19 pandemic. Frontiers in psychiatry. 2020; 11: 842. D0l: https://doi.org/10.3389/ fpsyt.2020.00842.

17. Restauri N., Sheridan A. D. Burnout and posttraumatic stress disorder in the coronavirus disease 2019 (COVID-19) pandemic: intersection, impact, and interventions. Journal of the American College of Radiology. 2020; 17(7):921-926. D0l: https://doi.org/10.1016/j.jacr.2020.05.021.

18. Budner $\mathrm{S}$. Intolerance of ambiguity as a personality variable. Journal of personality. 1962; 30(1): 29-50. https://doi. org/10.1111/j.1467-6494.1962.tb02303.x.

19. Soldatova G. U., Shaigerova L. A., Prokofieva T. Y. et al. Psychodiagnostics of personality tolerance. M.: Smyisl, 2008; 172 (in Russian).

20. Chesnokova I. I. Problema samosoznaniya v psikhologii [The problem of self-awareness in psychology]. Moscow: Nauka, 1977; 144. (in Russian).

21. Sardzhveladze N.I. Samootnosheniye lichnosti [Self-relation of personality]. In Ed. D. Ya. Raygorodskiy Psihologiya samosoznaniya [Psychology of self-awareness]. Samara: «BAKHRAH-M». 2000; 174-194. (in Russian).

The studies were carried out as part of the planned research work "Mechanisms of realization of adaptive-compensatory reactions of organism under various pathologies, (state registration No. 0117U002385;11BF036-01).

\section{ORCID and contributionship:}

Nataliia I. Pogorilska: 0000-0001-5297-1624 ${ }^{A, B, E, F}$

Roman Y. Synelnykov: 0000-0003-1634-7458 A, B,E

Borys I. Palamar: 0000-0003-2510-0713 A, B, C, D, E, F

Sergii V. Tukaiev: 0000-0002-6342-1879 A, B, C, E, F

Liudmyla L. Nezhyva: 0000-0001-9520-0694 A, C, E, F

\section{Conflict of interest:}

The Authors declare no conflict of interest.

\section{CORRESPONDING AUTHOR}

\section{Borys I. Palamar}

Bogomolets National Medical University

13 Taras Shevchenko Blvd, 01601 Kyiv, Ukraine

tel: +380672387654

e-mail: palamar.bi@ukr.net

Received: 07.10 .2020

Accepted: 12.04 .2021

A - Work concept and design, B - Data collection and analysis, C - Responsibility for statistical analysis,

D-Writing the article, $\mathbf{E}$-Critical review, $\mathbf{F}$ - Final approval of the article 